\title{
`* Эoumial
}

\section{Qnirtwe \\ MARINE BIOLOGIGAL ASSOCIATION \\ OP}

\section{THE UNITED KINGDOM.}

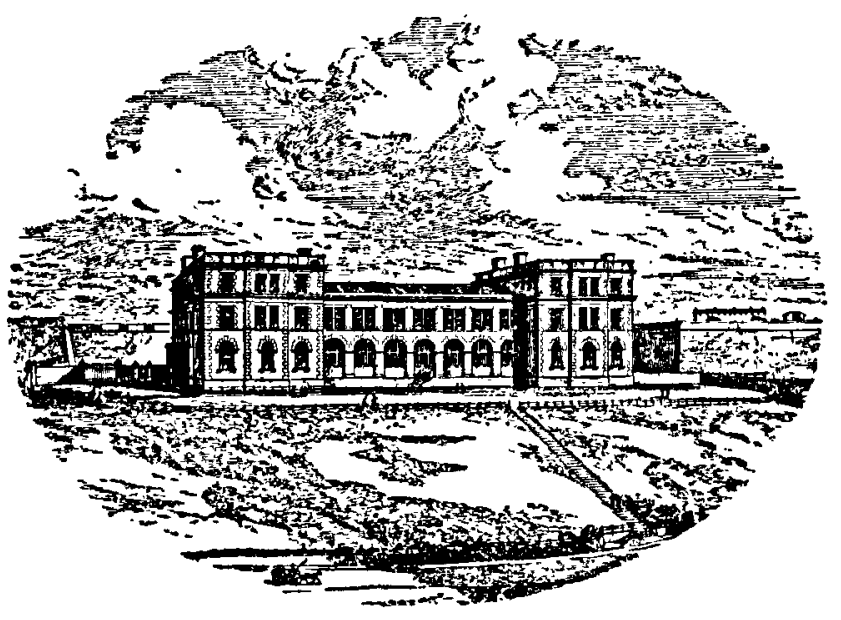

THF PLYMOUTH IABORATORY.

\section{VOLUME I (N.S.). \\ 1889-90.}

\section{PLYMOUTH : \\ PUBLISHED BY THE ASSOCIATION.}

Agents in London :-Messrs. Dousu \& Co., 37, Soho Square, W. 